\title{
NZGA PRESIDENT'S ADDRESS 2019 \\ Smarter pasture renewal plus objective thinking
}

Barenbrug, 2547 Old West Coast Rd, RD1, Christchurch 7671, New Zealand

gkerr@barenbrug.co.nz

Good morning. There are two parts to this address today. Mostly I'd like to give some thoughts around pasture renewal. But I would also like to conclude with some remarks as the outgoing President of the NZGA.

\section{Smarter pasture renewal}

Pasture underpins the industry we belong to - it is New Zealand's natural advantage. We can keep stock outdoors year-round, and can grow dry matter (DM) at a relatively low cost. Part of maintaining our productive pasture base is renewing pasture, a process I have been involved in for 30 years.

By 'renewal' I don't simply mean re-grassing. Renewal is addressing the underlying reasons for a pasture's underperformance, whether it be soil fertility, pests or anything else. This is an annual investment by the pastoral industry of $>\$ 300 \mathrm{~m}$, assuming the rate of renewal reported by the Pasture Renewal Charitable Trust (2013) of $8 \%$ for dairy-farmed area and 2.3\% for sheep and beef, and an $\$ 800 /$ ha expenditure for renewal. The renewal rate for individual farms varies widely (Kelly et al. 2011) and sheep and beef farms are significantly lower, partly due to the large area of hill and high country.

Looking at research papers on renewal published by the NZGA, there are many on physical processes (e.g. Glassey \& Reade 1986), sowing methods (e.g. Thom et al. 2011), and sowing depth (e.g. Woodman et al. 1990). But there are few papers and little research on how farmers set a renewal level (Stevens et al. 2007).

What I would like to suggest is, based on my experience, a lot of decisions are made subjectively and can be improved upon. We need to: think differently; use some current technologies differently; and capture renewal planning into some of the new technologies on the near horizon. This is the challenge I put to you today.

\section{Drivers for renewal}

It has been suggested there are five main drivers for renewal (Kerr et al. 2015):

1. Crop requirement: Where the farm systems requirement for summer or winter crop is calculated first, with pasture renewal being a by-product.

2. Historical: Where farms undertake a certain amount of pasture renewal each year, and the budget is set at this. These first two drivers are often linked.

3. Event response: For example replacing a pasture following a flood or pugging.

4. Development: Sowing as part of farm development.

5. Cost/benefit: This driver is focus of this talk, which is analysing the costs versus predicted benefits, to look to achieve the greatest gains for the smallest investment.

The first four reasons are the most common, and are important. But, I suggest few commercial farms undertake a cost/benefit approach to pasture renewal.

So how could this work? I will give two examples from dairy farms I have worked with. These principles are the same for sheep and beef farms, but dairy systems are much simpler to work with.

\section{Marlborough monitor farm}

This farm is run by Jason and Amber Templeman and an analysis of the estimated pasture growth (t DM/ha/ year) of individual paddocks for 2015-16 is shown in Figure 1 (data from Additional File 1). The data were back calculated from weekly pasture cover estimates, but could also have been created from grazing records. Similar to a feed wedge, paddocks are ranked from the best to worst performing.

The reason I am excited about this topic is that you see very large differences in yield across a typical of a dairy farm. The differences will be greater still on a sheep farm with several topographies.

There is also a lot of noise or error around these type of farm datasets, so we typically ignore differences of $\leq 2 \mathrm{tDM} / \mathrm{ha} /$ year.

The potential 'missing yield' can be estimated using the farm's best performing paddock (A2) as a starting point for a known potential yield, with the missing yield shaded in Figure 1. This analysis naturally leads you to first look at paddock B22 as a candidate for renewal, as it is underperforming by a very large $8.5 \mathrm{t} \mathrm{DM} / \mathrm{ha} /$ year.

The question when you look at Figure 1 is "how hard should we chase this missing yield?”. I will come back to this question.

On farms, not all paddocks are created equal. So, a smarter analysis is to divide farms into areas of different productive potential with the best paddock within each productive area used to indicate the potential performance of that group. 


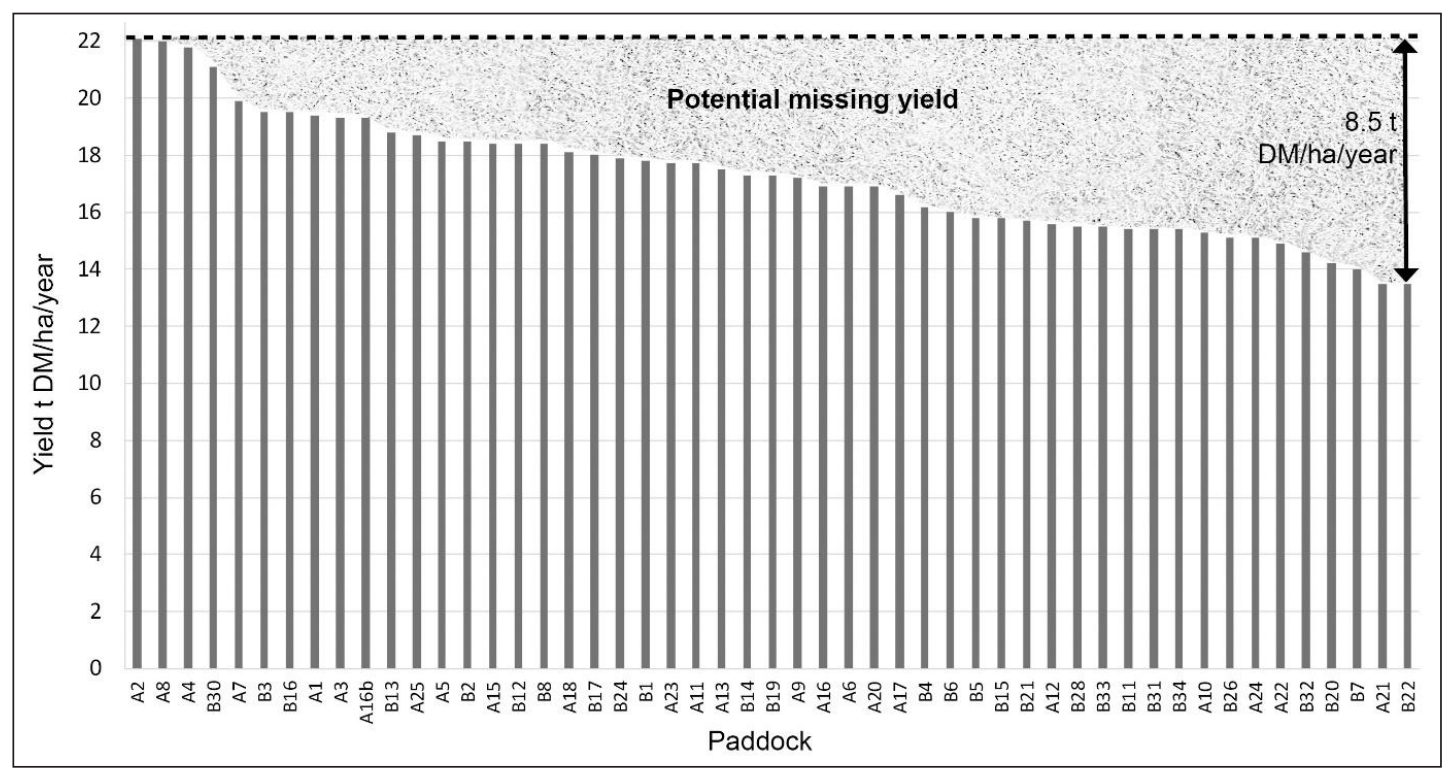

Figure 1 Estimated pasture yield (tDM/ha) for the Marlborough Monitor Farm for 2015-16. Shading shows potential missing yield based on performance of best paddock (A2).

The same data used to produce Figure 1 are presented Figure 2 in this way. By grouping the dry paddocks together, it can be seen that the potential gain from renewing paddock B22 is poor, reduced from $8.5 \mathrm{tDM} /$ ha estimated in Figure 1 to only $1.5 \mathrm{t} \mathrm{DM} / \mathrm{ha}$. The best renewal investment is normally, as here, the poorest performing paddocks on the best part of the farm.

Has anyone here seen a farmer do this sort of analysis?

\section{Typical renewal decisions?}

A great deal of the decisions around renewal I have seen in my career are made where the farmer goes around the property with a company person, looking for paddocks to renew.

The amount of renewal has been pre-determined by the need for crop and/or budget (drivers previously outlined), so they drive to several paddocks across the property, have a look, and generally agree "yes, this

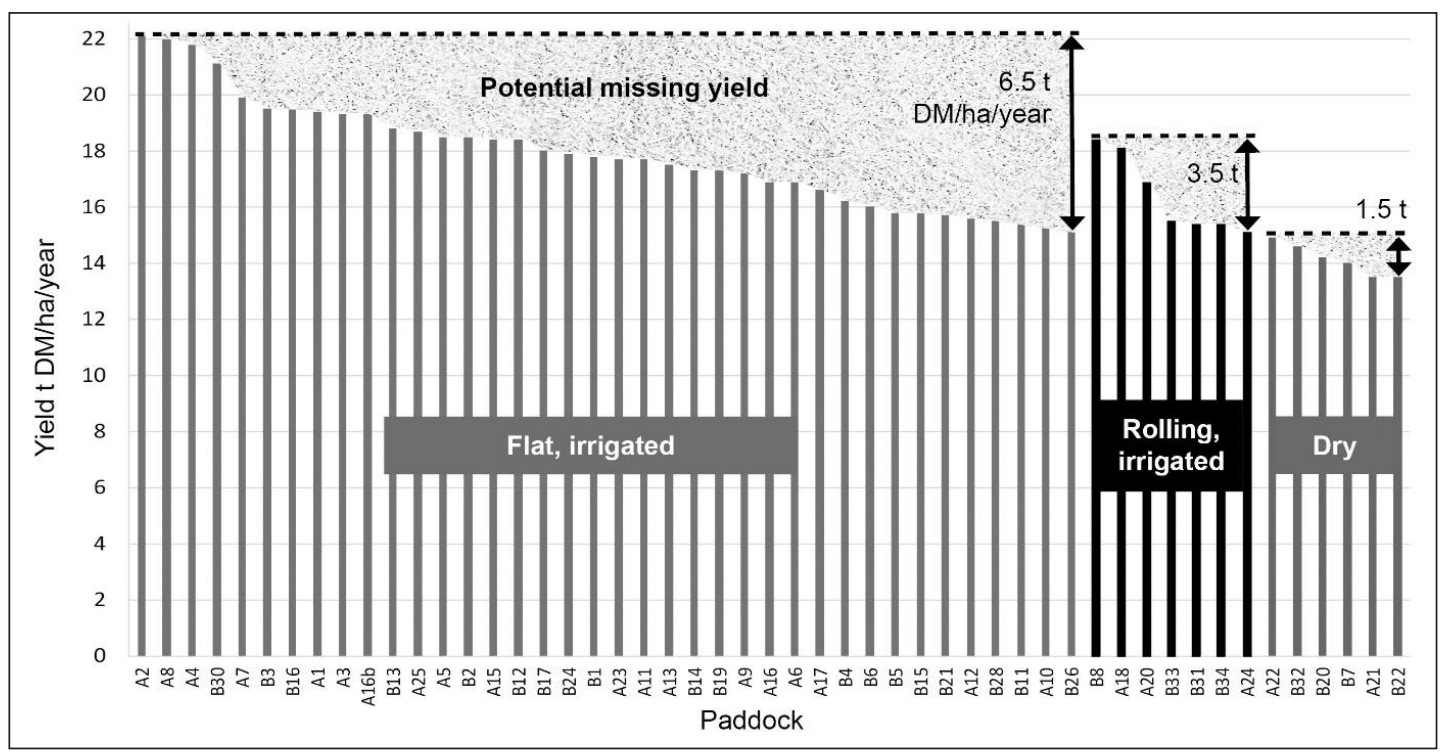

Figure 2 Estimated pasture yield (tDM/ha) for the Marlborough Monitor Farm for 2015-16 divided into three areas of different productive potential. Shading shows potential missing yield based on performance of best paddock in that farm area (A2, B8 and A22 respectively). 
looks like a good paddock to renew".

The question I have with this method is are we renewing under-performing paddocks or just ugly ones?? While these comments are somewhat tonguein-cheek, as many farmers have a good feel for their property, they do have some validity.

I have been on farms where we've carefully inspected what we know from grazing records to be very good and poor performing paddocks, with a high versus low carrying capacity respectively, and visually have not been able to tell the difference.

Also I remember challenging a very good farmer to do the paddock performance analysis for the last year, and at the end of it he was taken aback, as he had been going to renew six paddocks, of which five were in the top third of his farms performance.

I have worked with farmers doing no pasture renewal through to situations renewing over $30 \%$ of the farm area a year (e.g. Kerr et al. 2015) and, at both ends of this spectrum, decisions were based on expected returns for the investment.

\section{Typical renewal decisions?}

An additional benefit of paddock performance data is that it can be used to evaluate whether renewal has been successful or not, to better inform future investment decisions.

The Lincoln University Dairy Farm (LUDF) has been collecting paddock performance for the last 14 years in a similar way to those presented in Figure 2, but with the different productive areas of this property being their three soil types (Templeton, Wakanui and Temuka).

Over time, continual monitoring allows the return on the renewal investment to be estimated, as shown in Figure 3. While this is a complex graph to present, the concept is simple. The black bars are the season in which this paddock has been renewed (typically through spraying off, cultivating and re-sowing) and, in the years following, we expect to see a performance improvement over the preceding year(s).

I asked the question earlier "how hard should we chase the missing yield?". This analysis helps answer this question. If we are asking a farmer to do more renewal - we need to be confident we are getting an acceptable return for them. And, for the LUDF, it is about a $\$ 6500 /$ ha return in income, over 5 years, for around a $\$ 1000$ investment.

\section{Conclusions on renewal}

To conclude this first part of my address, the challenge I have given for the $>\$ 300 \mathrm{~m} /$ year investment into new pasture our industry makes is threefold:

1. we need to get smarter, collect and use the data we have to make better decisions on the amount of renewal that should be undertaken, as well as the identification of underperforming paddocks;

2. we need to automate these analysis to make them easier to do; and

3. ugliness is not a good way to assess pasture performance.

\section{My final remarks}

As today is the end of 13 years on the NZGA Executive Team for me, I would like to take the last 5 minutes to make a few comments regarding the Association going forward.

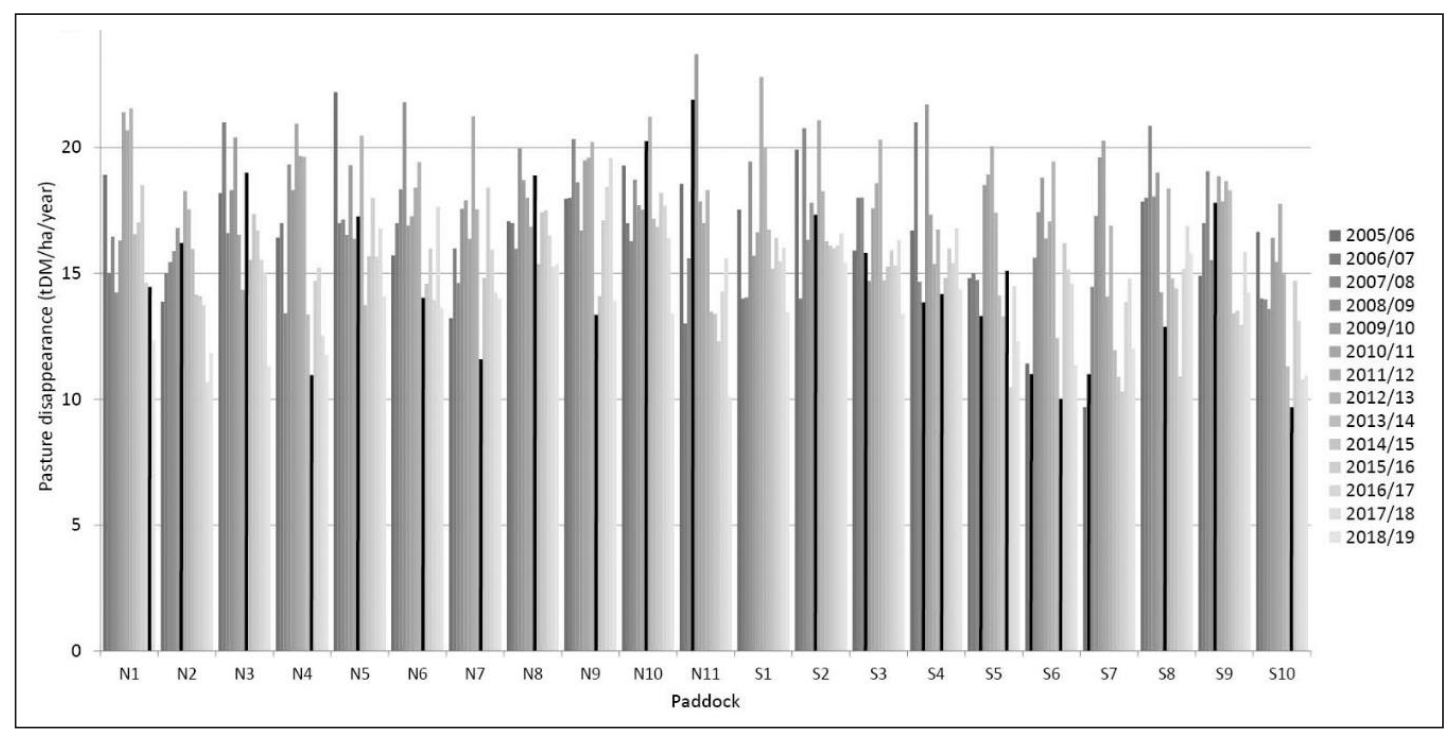

Figure 3 Estimated pasture disappearance (t DM/ha/year) of individual paddocks of the LUDF from 2005-2019. The black bars are the seasons in which paddocks were resown. 
We have been challenged in this conference by several speakers to link across the value chain to our customers - who we've heard are not necessarily predictable or logical.

And our customers are largely global, with views on what is "acceptable" in New Zealand farm systems coming from a very different place to us.

While I agree with the speakers that we must work to meet our customer demands, I do not entirely agree that "the customer is always right". Educating customers is also critical, as their views are equally formed from what they don't know, as well as what they do.

"Acceptable practices" for our industry to help educate our customers or the wider public must be developed through by good science in order to last.

But we are in a digital age of communication and miscommunication. One example I gave in my President's Address last year (Kerr 2019) was " $A$ glass of red wine is equivalent to an hour in the gym" reported by the Huffington Post (2015). This headline was purportedly based on a study at the University of Alberta, published in the Journal of Physiology (Dolinsky et al. 2012). But, the media overlooked that the trial was done with rats and didn't actually use red wine but a compound found in grape skins, which was given at a level equivalent to us each drinking 100-1000 bottles of red wine a day!

While humorous, it is a sad commentary on some of our media reporting that it is easy to find examples like this.

And with the digital, commercial age we live in the peer-reviewed, independent status of this Association is more important than ever. It is unique in this space in our industry.

Thank you very much to our family of sponsors who recognise this and support us.

We work in a great industry. Grazing pasture is natural - animals have done it for millions of years. And natural food will always be the most sought-after.

We have a great, unique Association that, over its 88 years, has built a very positive, passionate, as well as friendly, culture. It is probably the overseas visitors to our conference, and the envy they have of us, that best reminds us of what we have.

So, lastly, to everyone here I ask you to continue supporting the NZ Grassland Association, and the role it has in our industry. Thank you very much.

Additional Online File: Marlborough Monitor Farm Final Field Day Handout. Jason and Amber Templeman, Mahakipawa Farms Ltd. 5 May 2016. Available at: https://doi.org/10.33584/jnzg.2020.82.3425

\section{REFERENCES}

Dolinsky VW, Jones KE, Sidhu RS, Haykowsky M, Czubryt MP, Gordon T, Dyck JR 2012. Improvements in skeletal muscle strength and cardiac function induced by resveratrol contribute to enhanced exercise performance in rats. Journal of Physiology 590: 2783-2799. https://doi.org/10.1113/ jphysiol.2012.230490

Glassey CB, Reade JB. 1986. The elimination and replacement of wild tall fescue in northland dairy pastures. Proceedings of the New Zealand Grassland Association 47: 187-190. https://doi.org/10.33584/ jnzg.1986.47.1753

Huffington Post. 2015. A glass of red wine is the equivalent to an hour at the gym, says new study. Accessed: 21/10/2018 from: https://www. huffingtonpost.co.uk/2016/01/08/a-glass-of-redwine-is-the-equivalent-to-an-hour-at-the-gym-saysnew-study_n_7317240.html

Kelly S, Smith E, Brazendale R. 2011. Pasture renewal in the Waikato and Bay of Plenty regions: An overview of farmer practice, experience and attitudes. Pasture Persistence Symposium, Grassland Research and Practice Series 15: 21-24.

Kerr GA. 2019. NZGA President's Address 2018 - Science and objective thinking. Journal of New Zealand Grasslands 81: 7-10. https://doi. org/10.33584/jnzg.2019.81.418

Kerr GA, Brown J, Kilday T, Stevens DR. 2015. A more quantitative approach to pasture renewal. Journal of New Zealand Grasslands 77: 251-258. https://doi. org/10.33584/jnzg.2015.77.460

Pasture Renewal Charitable Trust. 2013. Results from Statistics NZ Agricultural Census for 2011-12. Reported by the Pasture Renewal Charitable Trust. http://www.pasturerenewal.org.nz/article/138.html. Accessed 25 September 2013

Stevens DR, Walcroft J, Casey MJ, Burggraaf VT, Fraser TJ, Webby R, Smeaton D, Lambert MG. 2007. Literature review on effects of pasture renewal in New Zealand and simulation modelling of those effects on whole farm profitability. AgResearch report prepared for the New Zealand Pasture Renewal Charitable Trust.

Thom ER, Fraser TJ, Hume DE. 2011. Sowing methods for successful pasture establishment - a review. Pasture Persistence Symposium. Grassland Research and Practice Series 15: 31-38.

Woodman RF, Doney RJ, Allan BE. 1990. Effects of drilling depth on seedling growth of seven dryland pasture species. Proceedings of the New Zealand Grassland Association 52: 167-170. https://doi. org/10.33584/jnzg.1990.52.1974 